\title{
Can groups be genuine believers? The argument from interpretationism
}

\section{Marvin Backes ${ }^{1}$ (iD}

Received: 24 September 2020 / Accepted: 3 June 2021 / Published online: 25 June 2021

(C) The Author(s) 2021

\begin{abstract}
In ordinary discourse we often attribute beliefs not just to individuals but also to groups. But can groups really have genuine beliefs? This paper considers but ultimately rejects one of the main arguments in support of the claim that groups can be genuine believers - the Argument From Interpretationism - and concludes that we have good reasons to be sceptical about the existence of group beliefs. According to the Argument From Interpretationism, roughly speaking, groups qualify as genuine believers because we can interpret (or predict) their behaviour in much the same way that we can interpret (or predict) the behaviour of individuals. While this argument may seem initially attractive, I argue that it is ultimately unsuccessful. In particular, I argue that the argument is unsuccessful even if one is generally sympathetic towards interpretationism. The reason for this, as we will see, is that a number of problems arise when we try to apply the interpretationist strategy - originally formulated with individual subjects in mind - to plural subjects or groups. In showing why the Argument From Interpretationism fails, the paper also brings into focus some more general constraints on the scope and applicability of interpretationism.
\end{abstract}

Keywords Group belief · Believers · Rejectionists · Interpretationism · Summativism · Acceptance

\section{Introduction}

In day-to-day discourse it is commonplace to attribute beliefs not just to individuals but also to groups. ${ }^{1}$ For instance, we say things like the following.

\footnotetext{
${ }^{1}$ For influential analyses of the notion of group belief see Gilbert's (1987, 1989) Joint Commitment Account and Tuomela's (1992) Positional Account.

Marvin Backes

marvin.backes@filosofi.uu.se

1 Department of Philosophy, Uppsala University, House 2, Thunbergsvägen 3H, 75126 Uppsala, Sweden
} 
(a) The conservative party believes that taxes should be lowered.

(b) The company believes that sales are going to decline.

(c) PETA believes that factory farming should be abolished.

But can groups really have genuine beliefs? Despite the ubiquitous data from ordinary language suggesting that they can, this question has given rise to a lively debate between what are sometimes called believers - those who hold that groups can indeed have genuine beliefs - and rejectionists, who deny this claim. ${ }^{2}$ According to rejectionists, talk of group belief is simply metaphorical or a form of 'loose talk'. We can distinguish between two different types of rejectionists. According to summativist rejectionists, attributing beliefs to groups is simply an indirect way of attributing beliefs to some or all of its members.

Summativist rejectionism When we ascribe beliefs to groups, we are indirectly ascribing beliefs to some or all of its members.

The following well-known and often cited proposal by Quinton (1975: p. 17) nicely captures this kind of rejectionist view.

Groups are said to have beliefs, emotions and attitudes and to take decisions and make promises. But these ways of speaking are plainly metaphorical. To ascribe mental predicates to a group is always an indirect way of ascribing such predicates to its members. With such mental states as beliefs and attitudes the ascriptions are of what I have called a summative kind. To say that the industrial working class is determined to resist anti-trade-union laws is to say that all or most industrial workers are so minded.

The second kind of rejectionist is very different from the first. They, like believers, accept that there are collective cognitive states which groups can instantiate but, for reasons to be discussed below, deny that belief is amongst these states. According to the most prominent proposals, group views are best understood as a species of acceptances rather than beliefs. In a slogan: groups may accept things but they cannot believe things. Let's call rejectionists of this kind acceptance rejectionists. ${ }^{3}$

Acceptance rejectionism When we attribute beliefs to groups, we are engaging in 'loose talk' - i.e. we are conflating belief and acceptance. There is no such thing as group belief, there are only group acceptances.

This paper is concerned with one of the central - and the perhaps strongest - positive argument in support of the claim that groups can be genuine believers, which, if successful, would also undermine both types of rejectionism. This argument, a version of which was previously proposed by Tollefsen (2002a, 2015), takes as a starting point interpretationism - roughly speaking, the view that all there is to being a

\footnotetext{
${ }^{2}$ Believers include Gilbert (2002, 2004) and Tollefsen (2002a, b, 2003, 2015). Rejectionists include Quinton (1975), Cohen (1989), Tuomela (2000), Wray (2001, 2003), Meijers (1999, 2002), Hakli (2006), and Lackey (2020). The terms believers and rejectionists were introduced by Tollefsen (2003) and Gilbert (2002) respectively.

${ }^{3}$ See, Cohen (1989), Tuomela (2000), Wray (2001, 2003), Meijers (1999, 2002), Hakli (2006).
} 
genuine believer is to be interpretable (or predictable) from the intentional stance - and concludes that since we can interpret (or predict) the behaviour of groups in much the same way that we can interpret (or predict) the behaviour of individuals, groups too can have genuine beliefs. I will call this the Argument From Interpretationism. If successful, this argument would go a long way towards establishing groups as entities capable of having beliefs. However, while the argument may seem initially attractive, whether the interpretationist strategy - which was originally formulated with individual subjects in mind - can straightforwardly be applied to plural subjects (i.e. groups or collectives) is a substantial metaphysical question. I argue that once we look at the Argument From Interpretationism in more detail, a number of different problems emerge which rejectionist can exploit and which ultimately make the argument unpersuasive. This is bad news for believers since the Argument From Interpretationism offered a particularly promising argument in support of their view. Finally, in diagnosing why the Argument From Interpretationism fails, the paper also brings into focus some more general issues surrounding the scope and applicability of the interpretationist framework.

In Sect. 2 I present some of the main arguments in support of rejectionism. In Sect. 3 I show why endorsing a metaphysically lightweight account of belief like interpretationism promises to be a particularly attractive strategy for believers. In Sect. 4 I briefly present and motivate the Argument From Interpretationism. Finally, in Sects. 5 and 6 I argue that the argument is less compelling than it may initially appear and anticipate responses on behalf of both summativist rejectionists and acceptance rejectionist.

\section{The rejectionists' challenge}

As mentioned above, there seems to be plenty of evidence from ordinary language usage suggesting that groups can have beliefs. So why would anyone question this? There are a number of arguments that may move someone towards rejectionism. As is to be expected, some of them are more persuasive than others.

Let's start with an argument that I think is likely to underwrite many peoples' initial scepticism about the existence of collective cognitive states in general and group beliefs in particular.

\section{The Physical Centre of Consciousness Argument}

P1. Having cognitive states - like beliefs - requires some sort of physical centre of consciousness (e.g. a brain) that generates and stores these beliefs.

$\mathrm{P} 2$. Groups don't have a physical centre of consciousness - i.e. they don't have brains.

C. Therefore, groups don't have cognitive states like beliefs.

While the Physical Centre of Consciousness Argument, or a version of it, might seem initially compelling it is not entirely uncontroversial. Note that (P1) presupposes that what it is to be in a cognitive state is to be in some sort of physical state. 
But, as believers have previously pointed out, philosophers have largely abandoned such type-identity theories of the mind according to which cognitive states (like beliefs) are identical to some type of physical state within the brain or some other information processing network. ${ }^{4}$ Hence, arguments like The Physical Center of Consciousness Argument are unlikely to impress believers. ${ }^{5}$

There are, of course, more sophisticated arguments in favour of rejectionism. For instance, summativist rejectionists might deny that we have good enough reasons to metaphysically commit ourselves to the existence of group beliefs (in addition to the beliefs of individuals which everyone of course accepts exist). And, if group beliefs are theoretically dispensable - for instance because we can analyse them in terms of individuals' beliefs - then it seems that we have good reasons to deny their existence and to omit them from our ontology. In fact, I take this to be the strongest argument in support of summativist rejectionism.

\section{The Dispensability Argument}

P1. Collective cognitive states are theoretically dispensable - i.e. there is no good reason to accept the existence of collective cognitive states like group beliefs.

$\mathrm{P} 2$. In the interest of parsimony, if something is theoretically dispensable, then we should reject it - i.e. we should exclude it from our ontology.

C. Therefore, we should reject the existence of collective cognitive states like group beliefs.

How might believers respond to this argument? Believers will likely want to reject (P1) - the claim that group beliefs are theoretically dispensable. How might believers argue for the indispensability of group beliefs? The perhaps most likely strategy for them is to try and find cases in which it might seem appropriate to attribute a belief to a group without any of its members holding the corresponding belief. Such cases, so the argument might go, would show that contra summativist rejectionists group beliefs cannot simply be analysed in terms of individual's beliefs and therefore are not theoretically dispensable. ${ }^{6}$ Specifically, we need them to explain the alleged propriety of group belief attributions in cases where none (or very few) of the members hold the belief in question. ${ }^{7}$ Consider, for instance, the following case. A committee is tasked with deciding whom to hire for a job. There are three candidates A, B, and C. Some members of the group believe that $\mathrm{B}$ should get the job and rank $\mathrm{C}$ lowest. Others think that $\mathrm{C}$ should get the job and rank B lowest. But all members rank $\mathrm{A}$ in the middle. After hours of deliberation the group compromises and decides that A should

\footnotetext{
4 See Tollefsen (2002a: p. 397).

${ }^{5}$ I think that there is a lot more to be said about this response to the Physical Centre of Consciousness Argument. Particularly, a lot more would need to be said about exactly what type of identity theory the argument commits us to and whether this form of identify theory is really as objectionable as believers suggest. But, since we can't pursue this issue further here, I will simply concede to the believer that, as things stand, the argument is unpersuasive.

6 Such arguments can be found in Gilbert (1989, 2004), Tollefsen (2015), Bird (2010). See also Lackey (2020).

7 Believers sometimes also provide examples that aim to show that some (or even all) members of a group believing some proposition is not sufficient for group belief. See, for instance, Gilbert (2004) or Tollefsen (2015). But these cases are less relevant to the argument at hand.
} 
get the job. In this case believers argue it would be appropriate to say that the group believes A should get the job despite the fact that none of its members believe this to be the case. If this is correct, then it seems that group beliefs are not theoretically dispensable after all. However, I think it is far from clear whether in these cases - where none of the members hold the relevant belief - it is really appropriate to say that the group holds the belief in question. ${ }^{8}$ Perhaps judgments will diverge on this issue, but in the example above it doesn't seem unreasonable for summativist rejectionists to deny that the group genuinely believes that A should get the job. Hence, the believers most likely response to The Dispensability Argument faces a serious worry: it relies quite heavily on a controversial interpretation of a range of cases - an interpretation which rejectionists might reasonably deny. At this stage, believers might concede this point and suggest that different people simply have different views about these cases. However, things won't be this easy for the believer; it is important to keep in mind that the summativist rejectionists' picture is more parsimonious and, therefore, the burden of proof seems to be on the believer. In other words, in the absence of convincing reasons for thinking that group beliefs are not theoretically dispensable, it seems that we have good reasons to be rejectionists.

As is to be expected, the arguments by acceptance rejectionist against believers are of a very different kind. Recall that acceptance rejectionist are sympathetic to the idea that groups can have cognitive states - they just deny that beliefs are amongst the cognitive states that groups are capable of having. Instead they hold that it is more appropriate to speak of group acceptances rather than group beliefs. Hence, the belief/acceptance distinction is central to the acceptance rejectionists' arguments against believers. ${ }^{9}$ Their arguments usually have the following general structure: they first identify a condition that is taken to be essential to the notion of belief and then, in a second step, argue that groups are somehow incapable of satisfying this condition. Various versions of these arguments have been defended in the literature. Here are some of the most prominent ones.

Cohen (1989) argued that, amongst other things, belief and acceptance have different phenomenologies. Believing, according to Cohen, comes with a certain phenomenology; a certain feeling of truth. "Belief that $\mathrm{p} \mathrm{...} \mathrm{is} \mathrm{a} \mathrm{disposition} \mathrm{to} \mathrm{feel} \mathrm{it}$ true that p." (1989: p. 368). And since groups don't seem to be capable of having these kinds of feelings, we might argue, they can't have beliefs.

\section{The Phenomenology Argument}

P1. Genuine beliefs have a certain phenomenology - they come with a certain feeling.

$\mathrm{P} 2$. Groups do not have the right physiological makeup to be capable of, or being disposed to, having these feelings.

C. Therefore, groups cannot have beliefs.

\footnotetext{
${ }^{8}$ Some believers have also acknowledged that our intuitions don't appear to be as strong in these kinds of cases. See, for instance, Tollefsen (2015: p. 13).

${ }^{9}$ For more on this distinction, see Cohen $(1989,1992)$, Bratman (1992), Engel $(1998,2000)$, Tuomela (2000).
} 
Alternatively, Wray (2001, 2003) and Meijers (1999, 2002) have argued that, broadly speaking, group views aren't genuine beliefs because they are not sensitive to the right kind of epistemic factors. For instance, a lot of people think that genuine beliefs, unlike acceptances, are truth-directed and therefore are sensitive only to truth-related factors (e.g. one's total evidence). ${ }^{10}$ In contrast, Wray and Meijers argue that group views are often influenced by distinctly non-epistemic factors. Particularly, they argue that groups adopt their views in light of their practical interests or their specific goals. And since this sensitivity to non-epistemic factors like practical interests is a feature commonly used to distinguish acceptances from genuine beliefs, ${ }^{11}$ Wray and Meijers conclude that group views are best understood not as beliefs but as acceptances.

\section{The Evidence/Goals Argument}

P1. Genuine beliefs are sensitive only to truth-related features - e.g. one's total evidence.

$\mathrm{P} 2$. The views of groups are sensitive to non-truth-related features and are adopted in light of the group's practical interests or their specific goals.

C. Therefore, group views are not beliefs.

Finally, Hakli (2006) has challenged the idea that groups can have genuine beliefs by appealing to the issue of doxastic voluntarism. Many people have endorsed the view that an essential hallmark of genuine beliefs, as opposed to acceptances, is that they are not under our direct control - i.e. we cannot believe or stop believing things at will. ${ }^{12}$ In the case of group views however, Hakli argues, it seems that they are very much under the group's control. In other words, unlike individuals, groups are free to adopt, revise, or abandon beliefs as they see fit. Hence, Hakli concludes, group views aren't beliefs but are more plausibly a species of acceptances.

\section{The Doxastic Voluntarism Argument}

P1. Genuine beliefs are involuntary - i.e. it is not under our direct control to adopt, revise, or abandon them at will.

$\mathrm{P} 2$. Group views are voluntary - i.e. they are under the direct control of the group.

C. Therefore, group views are not beliefs.

Together these arguments appear to make a compelling case against the idea that groups can be genuine believers. They each identify a condition that is widely taken to be essential to the nature of belief and make a compelling case for why group views do not satisfy this feature. So, it seems that both summativist rejectionists as well as acceptance rejectionists have prima facie plausible reasons to deny that groups can be genuine believers. How might believers respond to these arguments against their view? The next section addresses this question.

\footnotetext{
10 See, for instance, Bratman (1992), Engel (1998, 2000).

11 See, for instance, Cohen (1989, 1992), Bratman (1992), Engel (1998, 2000), Tuomela (2000), and Wray (2001: p. 325).

12 The locus classicus for this view is perhaps Williams (1970). See also, Cohen (1989), Bratman (1992), Engel (1998) Tuomela (2000). Note that there is a lot more nuance to this debate which I unfortunately cannot engage with here.
} 


\section{Two broad strategies for responding to the rejectionists}

Believers can respond to these arguments in one of two ways. First, they could take on and address the various arguments one-by-one. ${ }^{13}$ For instance, in response to summativist rejectionists, believers could try to come up with new cases that aim to show that group beliefs are not theoretically dispensable. And in response to acceptance rejectionists, believers might go through each of their arguments - e.g. The Phenomenology Argument, The Evidence/Goals Argument, and The Doxastic Voluntarism Argument - and try to show (both conceptually and/or empirically) that the allegedly essential features of belief assumed by these arguments are not actually essential; or, alternatively, that contra acceptance rejectionists, groups are in fact able to satisfy these essential features. One reason to be worried about the success of this strategy is that some believers have previously acknowledged that the dispute between believers and summativist rejectionists has "reached something of a stalemate" (Gilbert \& Pilchman, 2014, pp. 210 - 211). This concession might make us doubtful about whether believers will be able to successfully answer the various objections to their view.

A second, and I think more promising, strategy for believers would be to try and undermine the various rejectionist arguments wholesale - i.e. all at once. As is to be expected, this strategy will be radically different from the previous one. What might such a strategy look like? Note that many of the rejectionists' arguments outlined above, particularly those of the acceptance rejectionists, make substantial metaphysical commitments about the nature of belief - let's call them metaphysically heavyweight. ${ }^{14}$ Subsequently, it seems that believers might be able to avoid these kinds of arguments altogether by adopting a metaphysically lightweight account of belief - i.e. an account that places very few constraints on what's required for a system to qualify as a believer. More specifically, all that believers would need is an account of belief on which (1) groups qualify as genuine believers and (2) which is sufficiently lightweight to avoid the kind of objections that acceptance rejectionists have levelled against them. This strategy would also address the summativist rejectionists' challenge. Their objection that group beliefs are theoretically dispensable would not even get off the ground anymore, for the fact that groups can have beliefs would follow straightforwardly from the envisioned lightweight account of belief (see condition (1)). An important question at this stage then is what account of belief might deliver this result? The next section argues that interpretationism presents an appropriately lightweight account of belief that promises to satisfy both (1) and (2).

\footnotetext{
13 Tollefsen (2003) may be seen as an example of this strategy.

14 Someone might object that these commitments are very plausible and, as such, it might be a bit strong to call them metaphysically heavyweight. However, whether or not we find some constraint plausible or not does not change the fact that in accepting it we are making a metaphysical commitment - in this case about the nature of belief. As such, I'm using metaphysically heavyweight as a purely descriptive term rather than an evaluative one.
} 


\section{Group belief and interpretationism}

Interpretationism, championed famously by Daniel Dennett $(1978,1981,1987)$ and Donald Davidson (1984), roughly speaking, is the view that we can use interpretation - i.e. the process of ascribing cognitive states like beliefs and desires to subjects based on their actions - to draw conclusions about the mental. ${ }^{15}$ Particularly, interpretationists claim that there is an essential link between the mental and our ability to reliably explain and predict a subject's observable behaviour. ${ }^{16}$ Hence, if we want to determine whether some subject has beliefs, then, following interpretationism, we don't need to poke around their brain or engage in a priori reflection on the nature of belief but instead focus on observable behaviour. ${ }^{17}$ Abstracting away from some of the messy details surrounding the view for now, the central idea is the following: all that's required in order for some subject to count as a genuine believer is for their behaviour to be reliably interpretable or predictable from what Dennett called the intentional stance.

Interpretationism All there is to being a genuine believer is being a system whose behaviour is reliably interpretable (or predictable) from the intentional stance. ${ }^{18}$

What is the intentional stance? According to Dennett we rely on the intentional stance all the time to populate each other's heads with beliefs.

Here is how it works: first you decide to treat the object whose behaviour is to be predicted as a rational agent; then you figure out what beliefs that agent ought to have, given its place in the world and its purpose. Then you figure out what desires it ought to have, on the same considerations, and finally you predict that this rational agent will act to further its goals in the light of its beliefs. A little bit of practical reasoning from the chosen set of beliefs and desires will in many - but not all - instances yield a decision about what the agent ought to do; that is what you predict the agent will do. (Dennett, 1981: p. 61)

An essential feature of the interpretationist picture of course is that in so far as we are successful in interpreting or predicting the behaviour of some subject, we are licensed to conclude that the subject really does have those beliefs that we attributed to them. Here is a quick example.

It's looking rather gloomy outside and Susan is about to leave the house to go to work. Treating Susan as a rational agent with reasonable beliefs and desires, we can attribute to Susan (1) the belief that it will probably rain and (2) the desire to stay dry. This allows us to predict that Susan will take an umbrella (or some other protection from the rain) on her way to work. Since this is exactly what Susan does, interpretationism allows us to infer that Susan really does believe that it will probably rain and desires to stay dry.

\footnotetext{
15 See Child (1996: p. 8).

16 For a good critical discussion of what exactly this link may look like see Child (1996).

17 In fact, Dennett claims that behaviour is the only way to discern whether or not a subject has beliefs. (1981, p. 59).

18 See, for instance, Dennett (1981: p. 59).
} 
Note that interpretationism doesn't require that this strategy be infallible. Perhaps on this occasion Susan doesn't form the belief that it is going to rain (maybe she is overly optimistic about the weather); or, perhaps Susan for some reason doesn't mind getting rained on. However, as Dennett points out this would not threaten interpretationism. All that's required is that the interpretationist strategy be generally reliable.

This naturally leads to questions about the scope of interpretationism. What kinds of things are reliably interpretable or predictable from the intentional stance and therefore qualify as genuine believers? And importantly, do groups qualify? If they did, this would be good news for believers.

Now, on the surface it appears that often we can accurately interpret and predict the behaviour of groups. In fact, it seems like in many cases we can interpret and predict the behaviour of groups - e.g. organisations, families, special interest groups, political parties, etc. - in much the same way that we can interpret and predict the behaviour of individuals. For instance, consider the following two examples proposed by Tollefsen $(2002 \mathrm{a}, \mathrm{b})$.

Navy Suppose we want to explain the incidents of gunfire during a naval blockade. We read the official rules of engagement published to govern Navy operations. These rules embody the Navy's rational point of view. We can then explain why the Navy sometimes fires at other ships. Under certain conditions, specified in its rules of engagement, the Navy will fire at anyone it believes to have hostile intent. (402). ${ }^{19}$

Ford Consider the predictions we make about car companies. What will Ford Motor Company do in response to the rise in gas prices? If Ford is rational, then it will act so as to maximize profits. Because Ford wants to avoid losing money on its line of large vehicles and believes that individuals are less likely to buy large vehicles during a time at which gas prices are high, we can predict that Ford will discount its large vehicles. (ibid).

The conclusion we might draw from these examples, and indeed the conclusion that Tollefsen draws, is that if interpretationism is correct, then it appears that groups can be genuine believers. We might call this the Argument From Interpretationism.

\section{Argument From Interpretationism}

$\mathrm{P} 1$. All there is to being a genuine believer is being a systems whose behaviour is reliably interpretable (or predictable) from the intentional stance - i.e. Interpretationism is true.

$\mathrm{P} 2$. Groups are system whose behaviour is reliably interpretable (or predictable) from the intentional stance

C. Therefore, groups are genuine believers.

What should we make of this argument? If it is successful, then it seems that we have good reasons for becoming believers. Moreover, the argument would avoid and/or undermine the various objections by rejectionists outlined above, for the fact that groups can be genuine believers would follow straightforwardly from an

19 Tollefsen cites Clark (1994) as an inspiration for this example. 
interpretationist approach towards cognitive states and the mind in general. ${ }^{20}$ Now, rejectionists could of course simply reject interpretationism. This would stop the Argument From Interpretationism in its tracks. But this strategy would do little more than to reduce the dispute between believers and rejectionists to a more general dispute over the viability of interpretationism. This, I take it, wouldn't do much to advance the debate.

The remainder of the paper will be concerned with a different strategy. I will argue that even if we are generally sympathetic towards interpretationism, there are still good reasons to think that the Argument From Interpretationism fails. Here is why. The Argument From Interpretationism, while perhaps initially compelling, assumes without much scrutiny that the interpretationist framework - which was originally proposed with individual subjects in mind - can straightforwardly be applied to plural subjects (i.e. groups or collectives). Whether this is really the case however is a substantial metaphysical question. And, as we will see, once we start looking at the details involved in applying the intentional strategy to plural subjects a number of problems emerge. In the next two sections I will bring these obstacles into focus and show how both summativist rejectionists and acceptance rejectionist might respond to the Argument From Interpretationism.

\section{Against the argument from interpretationism: summativist rejectionists}

Recall that according to summativist rejectionists talk of group beliefs is purely metaphorical and just an indirect way of talking about the beliefs of some of its members. This general picture, on which only individuals have genuine cognitive states, is likely to play a central role in how summativist rejectionists will respond to the Argument From Interpretationism. Below I will outline two different ways in which summativist rejectionists might respond to it.

\section{The Target Challenge}

The first option for summativist is to question whose behaviour we are actually interpreting orð predicting when we seemingly interpret or predict what some group is likely going to do. The Argument From Interpretationism of course assumes that we interpret or predict the behaviour of the group itself, but summativist rejectionists might reasonably challenge this assumption. More specifically, summativist rejectionists might argue that although we sometimes talk as if we are interpreting or predicting the behaviour of groups, what we are really interpreting and predicting in these cases is simply the behaviour of some of its members. Let's call this the Target Challenge. For example, consider again Tollefsen's two examples discussed earlier, Navy

\footnotetext{
${ }^{20}$ Note that the Argument From Interpretationism remains neutral on the metaphysical question of what exactly we take cognitive states or mental states to be. For instance, Tollefsen (2015) endorses a version of dispositionalism according to which cognitive states are dispositional states - i.e. states that characterise how something will behave, or function, under certain circumstances (p. 199). But note that the argument does not presuppose any particular view about the nature of cognitive states.
} 
and Ford. summativist rejectionists might argue that we can explain why the Navy sometimes fires at other ships or predict that Ford will discount its large vehicles because we can interpret or predict the behaviour of some of its operative members - i.e. members that are responsible for, or particularly involved in, decision making. ${ }^{21}$ For the two groups in question - the Navy and Ford Motor Company - the operative members might be high-ranking navy officers and Ford executives respectively. ${ }^{22}$

At the heart of the Target Challenge is the following competing conjecture.

Competing conjecture When we explain or predict the actions of some gr - e.g. the Navy or the Ford Motor Company - we are only doing so indirectly; the behaviour that we are directly interpreting or predicting from the intentional stance is that of some of its membe - e.g. that of high-ranking navy officers or that of Ford executives.

If this competing conjecture is correct, then interpretationism would only support the claim that some members of the group have cognitive states like beliefs, which is of course uncontroversial. But it wouldn't follow that the group itself has any beliefs. In fact, all that summativist rejectionists need is that their competing conjecture be at least as plausible as the believer's claim that we can interpret or predict the behaviour of groups directly; and I take it that this is the case. Believers would have to somehow show why the competing conjecture is untenable. Importantly however, we don't need to leave things here. Below I will offer an argument in support of Competing Conjecture.

Let's start by considering the following case. You are driving down the road with another car in front of you. Now, as is to be expected, you will be able to make a lot of accurate predictions about what the car is going to do. For instance, you'll be able to reliably predict when the car is going to stop (e.g. at red lights), when it is going to start up again (e.g. when the light turns green), when it is likely to go fast (e.g. when there's little traffic), when it is going to go slow (e.g. when there's lots of traffic), etc. But, of course no one would seriously conclude from this that the car in front of you

\footnotetext{
21 See, for instance, Tuomela (2004), Lackey (2016), and Silva (2019).

22 An anonymous reviewer made the helpful observation that both Tollefsen's and my discussions of the Argument From Interpretationism focus largely on hierarchical groups - i.e. groups with operative members. In light of this, the reviewer questioned whether the Target Challenge will also apply to less structured groups - e.g. an egalitarian collective with a consensus decision procedure. I do think that the Target Challenge generalises to such groups. One legitimate worry when it comes to egalitarian collectives with a consensus decision procedure is whether we'd actually be able to reliably predict their behaviour in the first place. In many cases - particularly when we know very little about the goals/desires of the members and the beliefs we can reasonably attribute to them - I think it's safe to say that we won't be able to reliably predict what a group is going to do. In this case it seems that interpretationism wouldn't support the claim that these groups have genuine beliefs to begin with. Alternatively, if we do have a pretty good idea what goals and desires the collective's individual members have and what beliefs we can reasonably attribute to them, then we may be able to reliably predict what the group is going to do. But in this case it seems like the Target Challenge will gain traction again. After all, it is no longer clear whether we are predicting the actions of the group directly or whether we are just doing so indirectly because we can reliably predict the behaviour of some - i.e. a sufficient number - of its members. Hence, it seems that those who want to treat egalitarian collectives as genuine believers face a dilemma. Moreover, even if we could find an egalitarian collective with a consensus decision procedure whose behaviour we could reliably predict but which could somehow escape the Target Challenge, then, as the reviewer rightfully pointed out, there would still be the Predictive Power Challenge (discussed below) that believers would have to address.
} 
therefore has beliefs. Why would we not draw this conclusion? Presumably because we acknowledge that it is not really the behaviour of the car itself that we are predicting but the behaviour of the driver. And that the driver has the relevant beliefs is of course something everyone will likely accept. These considerations point towards a more general constraint on the use of the intentional strategy along the following lines.

Target condition When we reliably interpret or predict the behaviour of some system $X$, but some distinct system $Y$ is somehow responsible for the behaviour of $X$, then we are in fact reliably interpreting or predicting the behaviour of $Y$ and are only indirectly (if at all) interpreting the behaviour of $X .^{23}$

An important question then is whether in the case of groups we have reason to believe that there is some other system that is ultimately responsible for its behaviour. And here summativist rejectionists may point out that the behaviour of a group is ultimately determined by the decisions of at least some of its members. For instance, in Navy it seems plausible that certain high-ranking officers are ultimately responsible for the actions of the navy. Similarly, in Ford it seems plausible that some of Ford's executives are responsible for the company's discounting/pricing decisions. Indeed, we may think that the operative members of these groups are relevantly similar to the driver of the car above: both of them are ultimately responsible for the behaviour of the systems of which they are in charge. Hence, summativist rejectionists may appeal to the Target Condition to support their competing conjecture and ultimately to reject (P2) of the Argument From Interpretationism. ${ }^{24}$

\section{The predictive power challenge}

The second objection is very different from the first. Unlike the Target Challenge, it is not concerned with whose behaviour we are actually predicting when we apply the intentional strategy to groups. Instead, this objection holds that even if we were to concede that we sometimes really do apply the intentional stance directly to groups (rather than to some of its members) in order to predict their behaviour, once the interpretationist proposal has been sufficiently clarified it still wouldn't follow that groups are genuine believers.

\footnotetext{
23 There will likely be different ways of cashing out the relevant notion of responsibility. I will here simply assume a simple causal notion of responsibility according to which Y is responsible for X's behaviour if Y is causally responsible for X's behaviour. But I am open to the idea that there may be other, non-causal, notions of responsibility that may be used to precisify the Target Condition.

24 I thank an anonymous reviewer for suggesting that it might be helpful to say something about socalled divergence cases - i.e. cases in which a group seemingly believes that p even when no (or very few) of its members believe p. After all, for many believers these cases play a central role in motivating the idea that group belief cannot be straightforwardly reduced to the beliefs of its members as summativist rejectionists propose. Interestingly, Tollefsen does not consider divergence cases when discussing the Argument From Interpretationism. Now, on an interpretationist picture of belief, divergence cases would have to have the following structure: (a) we would have to be able to reliably predict what a group that's behaving rationally is likely going to do without (b) being able to reliably predict what some of its members are likely going to do assuming they too behave rationally. However, I take it that whether there are convincing cases that uncontroversially satisfy both (a) and (b) is largely an open question. For instance, the reviewer considers a variant of Navy in which no individual navy officer believes they should fire at a ship but the navy's rule of engagement (to which they are jointly beholden) stipulate they should fire given the circumstances. In this case the reviewer suggests that when we explain or predict
} 
Note that in its slogan form - all there is to being a genuine believer is to be interpretable (or predictable) from the intentional stance - interpretationism would have the consequence that almost anything qualifies as a believer. For instance, we could use the intentional stance to predict the behaviour of simple organisms like clams and insects, plants, and even artifacts and inanimate objects like heat-seeking missiles, chess computers, thermostats, even a lectern. ${ }^{25}$ But few people, including Dennett, would of course want to say that that all of these entities really do have genuine beliefs. In short, it seems like in its slogan form the intentional strategy seems to over-generate - i.e. it attributes beliefs to too many things. ${ }^{26}$

Now, Dennett was of course aware of this issue. Below is a well-known passage in which he acknowledges and addresses this worry.

Does our definition of an intentional system exclude any objects at all? For instance, it seems the lectern in this lecture room can be construed as an intentional system, fully rational, believing that it is currently located at the center of the civilized world (as some of you may also think), and desiring above all else to remain at the center. What should such a rational agent so equipped with belief and desire do? Stay put, clearly - which is just what the lectern does. I predict the behaviour, accurately, from the intentional stance, so is it an intentional system? If it is, anything at all is.

What should disqualify the lectern? For one thing, the strategy does not recommend itself in this case, for we get no predictive power from it that we did not antecedently have. We already knew what the lectern was going to do -

\section{Footnote 24 (continued)}

the behaviour of the navy, which does fire at the ship, it seems natural to cite its collective belief rather than any individual officer's belief, since no officer in fact has this belief. This would threaten the Target Challenge. But, it seems that summativist rejectionists could reply as follows. Given the position and purpose of navy officers, it is reasonable to attribute to them the belief (or commitment) that they should follow the navy's rules of engagement (even if they happen to conflict with their personal views). And, it is this belief (or commitment) that allows us to reliably explain and predict their behaviour and by extension the behaviour of the navy - in this case the gunfire. If this is right, then navy officers do in some sense - e.g. in virtue of their commitment to the navy's rules of engagement - believe they should fire at the ship, despite the fact that they would act differently if things were entirely up to them. In short, it seems to me that the case can reasonably be understood as a case of conflicting beliefs and in this case the Target Challenge would gain traction. In general, I suspect that on an interpretationist view of belief summativist rejectionists will have quite a bit of room for maneuvering when it comes to dealing with alleged divergence cases. Note also that even if believers were ultimately successful at finding such cases - which would certainly be an interesting result in its own right - this would not affect the argument put forward on behalf of acceptance rejectionists in Sect. 6 .

25 All we would have to do is to attribute various beliefs to the various systems and in so far as their behaviour would fit those beliefs, we would be licensed to conclude that these systems really do have these beliefs. Here are some examples from Dennett (1981, p. 65), "Once a clam believes there is danger about, it will not relax its grip"; "The chess playing computer will not take your knight because it knows that there is a line of ensuing play that would lead to losing its rook..."; "...the thermostat will turn off the boiler as soon as it comes to believe the room has reached the desires temperature.".

${ }^{26}$ Interestingly, Tollefsen (2015: p. 102) briefly considers this issue but then quickly dismisses it as a serious worry for believers. 
namely nothing - and tailored the beliefs and desires to fit in a quite unprincipled way. ${ }^{27}$ (1981, p. 66)

As we can see, Dennett deals with the over-generation worry by essentially conceding that being interpretable or predictable from the intentional stance is not in fact sufficient for something to count as a genuine believer - i.e. being predictable or interpretable from the intentional stance is not all there is to being a true believer. Instead, we see Dennett qualifying the interpretationist proposal: the intentional strategy also needs to give us predictive power that we did not antecedently have. And it is this condition that disqualifies things like simple animals, plants, and artifacts from counting as genuine believers. As Child (1996:p. 43) puts it, "So the ascription of attitudes to thermostats, or simple creatures, is surplus to explanatory requirements in a way that their ascription to human beings is not." Following Dennett then we should replace the earlier version of Interpretationism with Interpretationism*.

Interpretationism* A system qualifies as a genuine believer as long as (1) its behaviour is reliably interpretable (or predictable) from the intentional stance and (2) applying the intentional strategy to the system yields new predictive power that we didn't antecedently have.

An important question then is whether collective agents like groups can satisfy Interpretationism* - i.e. whether applying the intentional stance to groups gives us new predictive power that we didn't antecedently have. And I think this is something that summativist rejectionists may reasonably deny. Here is why.

In order to predict what some group is going to do, we might argue, we first need to make some assumptions about its members - e.g. their beliefs, their aims, their desires, etc. If we don't do this, then it seems like we won't be able to reliably predict what the group is going to do. It appears then that our ability to reliably predict the behaviour of some group depends in important ways on our ability to accurately predict the behaviour of at least some of its members. From here, summativist rejectionists, might draw the following conclusion: for any group, once we have applied the intentional stance to at least some of its members we don't learn anything new if we then also apply it to the group itself. In other words, applying the intentional strategy to groups seems to yield no predictive power above and beyond that which we get from applying the intentional strategy to some of its members. And, as a result, doing so would be entirely surplus to our explanatory needs. ${ }^{28}$

For instance, consider again Tollefsen's two cases, Navy and Ford. It seems that once we attribute the relevant beliefs and desires (as specified in the two cases) to the high-ranking officers and the Ford executives respectively, we can plausibly explain

\footnotetext{
27 My italics.

28 In previous work, Gilbert (2000) suggested that explaining scientific change requires attributing beliefs to scientific communities. For instance, Gilbert has argued that attributing beliefs to groups of scientists allows us to explain the stability and conformity of scientific communities, what lines of inquiry will/won't be pursued, and even to predict who is most likely to challenge convention. However, Fagan (2011) has shown that summativists too can straightforwardly explain these patterns and argued that group beliefs, for this reason, are explanatorily idle. Relatedly, Thagard (2010) has argued that social phenomena like economic crises can, against what believers might suggest, be explained without any appeal to group beliefs.
} 
why the navy sometimes fires at other ships and predict that Ford executives will discount its large vehicles. And, so the argument may continue, once we are in a position to reliably predict what the high-ranking navy officers and the Ford executives are going to do, we get no additional predictive power from applying the intentional strategy to the relevant groups - i.e. the Navy or the Ford Motor Company. Put somewhat more flippantly, summativist rejectionists might argue that groups are a bit like Dennett's lectern when it comes to the intentional strategy, for treating them as intentional systems affords us no predictive power that we didn't already have.

As we can see, summativist rejectionists have multiple options for responding to the Argument From Interpretationism. First, they might appeal to The Target Challenge to put pressure on (P2). But, even if believers could somehow respond to The Target Challenge, there would still remain the Predictive Power Challenge which, by replacing Interpretationism with Interpretationism*, puts pressure on (P1). Hence, in order to defend the Argument From Interpretationism believers will have to respond to both challenges.

\section{Against the argument from interpretationism: acceptance rejectionists}

While the Target Challenge and the Predictive Power Challenge will of course also be available to acceptance rejectionists, it is important to keep in mind that they differ from summativist rejectionists in important respects. Recall that acceptance rejectionist, unlike summativist rejectionists, are generally sympathetic to the idea that groups can have genuine cognitive states and only deny that belief is amongst the states that groups are capable of instantiating. More specifically, as we have seen, acceptance rejectionists hold that group views are best understood as acceptances rather than beliefs. Hence, it seems that for acceptance rejectionists an arguably more satisfactory reply to the Argument From Interpretationism would be one that focuses on the belief/acceptance distinction. Below I will elaborate such a reply.

First, acceptance rejectionists might point out that when it comes to observable behaviour alone it is very difficult to determine whether a subject merely accepts some proposition or whether they believe it. For instance, if you know that I desire to go to the bank and you see me turn left at the next corner, it doesn't seem like you would be able to tell from my behaviour alone whether I accept that the bank is to the left or whether I genuinely believe it. In other words, it seems like observable behaviour alone won't allow us to discriminate between genuine beliefs and mere acceptances - behaviour simply doesn't seem fine-grained enough for this task. Moreover, if we look at the aforementioned criteria that people have used to distinguish between belief and acceptances, we notice that none of them relate to differences in observable behaviour. The reason for this, we might speculate, is precisely because people have recognised that observable behaviour alone doesn't allow us to discriminate between belief and acceptance. 
These considerations, we might think, suggest that interpretationism faces a previously overlooked underdetermination issue: it appears that there are a number of pro-attitudes - e.g. acceptance and belief - which can be used to explain and predict the behaviour of groups. For instance, in Tollefsen's Ford example it doesn't seem like we necessarily need to attribute to Ford Motor Company the belief that individuals are less likely to buy large vehicles during a time at which gas prices are high in order to predict that they will discount their large vehicles. It seems like we could just as easily and reliably predict their behaviour if we assume that Ford accepts that individuals are less likely to buy large vehicles during a time at which gas prices are high. If this is correct, then it seems that we cannot straightforwardly infer from observable behaviour alone whether a subject believes some proposition or whether they merely accept it.

Now, this under-determination issue of course raises a more general worry for the intentional strategy. If there exist a number of pro-attitudes that can be used to reliably interpret or predict a subject's behaviour, then what should we make of the interpretationist slogan that all there is to being a true believer is for one's behaviour to be interpretable (or predictable) from the intentional stance? One option would be to take rejectionism's inability to accommodate the belief/acceptance distinction as a reason to reject interpretationism outright. While this is of course a live option, recall that I am more interested in objections to the Argument From Interpretationism that do not involve an outright rejection of interpretationism. Fortunately, there is another option. All that acceptance rejectionists who are generally sympathetic towards interpretationism would have to do is to modify the interpretationist slogan slightly.

Interpretationism** All there is to being a genuine believer or a genuine accepter is being a system whose behaviour is reliably interpretable (or predictable) from the intentional stance. ${ }^{29}$

This disjunctive account preserves the central tenet of interpretationism - namely, that there is an essential link between the mental and our ability to reliably explain and predict a subject's observable behavior - and should be welcomed by acceptance rejectionists. After all, Interpretationism** is compatible with the idea that groups can have genuine cognitive states - a position that acceptance rejectionists endorse - but it doesn't entail that groups are genuine believers. ${ }^{30}$

How might believers respond to this objection? The perhaps most promising strategy for believers at this stage would be to reject the traditional belief/acceptance distinction altogether. In fact, Tollefsen (2003) previously proposed this move by

\footnotetext{
${ }^{29}$ One might question how substantial of a modification this is and whether in the end it doesn't end up undermining interpretationism after all. I'm inclined to think that interpretationists like Dennett wouldn't be too worried about this issue. After all, they are primarily concerned with the question of when a system has intentional states in general rather than when a system has some particular intentional state. Hence, I don't think interpretationists would be particularly worried if they were told that the intentional strategy also works with acceptances. For believers however, whose argument relies on the idea that the intentional strategy works for beliefs specifically, this modification is of course bad news.

${ }^{30}$ In previous work, Tollefsen (2003) suggested that if rejectionists deny the existence of group beliefs, then they will also need to deny the existence of group acceptances. My argument here shows that this is not necessarily the case.
} 
suggesting that we follow Clarke (1994) and hold that accepting P entails believing $\mathrm{P}$ (at least to some degree). But, this is a very costly and generally unpopular move. After all, the belief/acceptance distinction and the idea that we can accept claims (e.g. for the purpose of an argument) without believing them seems highly plausible and, as discussed earlier, is widely endorsed in the literature. As a result, responding to acceptance rejectionists by denying the belief/acceptance distinction doesn't seem to be a particularly attractive strategy for believers. Hence, in so far as believers had hoped that opting for a metaphysically lightweight account of belief like interpretationism would put them in a better position to respond to the various arguments put forward by acceptance rejectionists, they will likely be disappointed.

\section{Conclusion}

In this paper I considered but ultimately rejected one of the main arguments in support of the claim that groups can have genuine beliefs: the Argument From Interpretationism. This argument concludes that groups have genuine beliefs because it appears that we can reliably interpret and predict their behaviour. I have argued that this argument is less persuasive than it may initially seem and anticipated replies on behalf of both summativist rejectionists and acceptance rejectionists. Importantly, I have argued that the argument fails even if we are broadly sympathetic towards interpretationism. A general lesson we have learned along the way is that the intentional strategy, which was originally formulated with individual subjects in mind, cannot be straightforwardly applied to plural subjects - i.e. groups. Finally, this paper highlighted why the failure of the Argument From Interpretationism is particularly bad news for believers. As we have seen, the best strategy for believers to respond to the various objections raised by rejectionists is to adopt a metaphysically lightweight account of belief and interpretationism appeared to be a particularly promising candidate. But, what the arguments in this paper have shown is that interpretationism won't help believers after all. So, it seems that on neither metaphysically heavyweight nor a suitably lightweight account of belief do groups qualify as genuine believers. Now, perhaps believers will be able to find a different account of belief that supports their view. Recall that such an account would have to satisfy the following two constraints: (1) groups need to qualify as genuine believers and (2) the account needs to be sufficiently lightweight to avoid the kind of objections raised by acceptance rejectionists. But currently it is far from clear what this alternative may be or what it might look like. Hence, I conclude that we have good reasons to be sceptical about the idea that groups can be genuine believers.

Acknowledgements I want to thank Matti Eklund and three anonymous referees for their helpful comments on earlier versions of the paper. I also want to thank the Wenner-Gren Foundations in Sweden for supporting my current Research Fellowship at Uppsala University. 
Funding Open access funding provided by Uppsala University.

Open Access This article is licensed under a Creative Commons Attribution 4.0 International License, which permits use, sharing, adaptation, distribution and reproduction in any medium or format, as long as you give appropriate credit to the original author(s) and the source, provide a link to the Creative Commons licence, and indicate if changes were made. The images or other third party material in this article are included in the article's Creative Commons licence, unless indicated otherwise in a credit line to the material. If material is not included in the article's Creative Commons licence and your intended use is not permitted by statutory regulation or exceeds the permitted use, you will need to obtain permission directly from the copyright holder. To view a copy of this licence, visit http://creativecommons.org/licen ses/by/4.0/.

\section{References}

Bird, A. (2010). Social knowing: The social sense of "scientific knowledge." Philosophical Perspectives, 24(1), 23-56.

Bratman, M. (1992). Practical reasoning and acceptance in a context. Mind, 101, 1-16.

Child, W. (1996). Causality, interpretation, and the mind. Oxford University Press.

Clark, A. (1994). Beliefs and desires incorporated. Journal of Philosophy, 91, 404-425.

Clarke, D. (1994). Does acceptance entail belief? American Philosophical Quarterly, 31(2), 145-155.

Cohen, J. (1989). Belief and acceptance. Mind, 98(391), 367-389.

Cohen, J. (1992). An essay on belief and acceptance. Clarendon Press.

Davidson, D. (1984). Inquiries into truth and interpretation. Oxford University Press.

Dennett, D. (1978). Brainstorms. MIT Press.

Dennett, D. (1981). True believers: The intentional strategy and why it works. In A. F. Heath (Ed.), Scientific explanation: Papers based on herbert spencer lectures given in the university of Oxford (pp. 150-167). Clarendon Press.

Dennett, D. (1987). The intentional stance. MIT Press.

Engel, P. (1998). Believing, holding true, and accepting. Philosophical Explorations, 1(2), 140-151.

Engel, P. (2000). Believing and accepting. Kluwer Academic Publishers.

Fagan, M. (2011). Is there collective scientific knowledge? Arguments from explanation. Philosophical Quarterly, 61(243), 247-269.

Gilbert, M. (1987). Modelling collective belief. Synthese, 73, 185-204.

Gilbert, M. (1989). On social facts. Routledge.

Gilbert, M. (2000). Collective belief and scientific change. In M. Gilbert (Ed.), Sociality and responsibility: New essays in plural subject theory. Rowman \& Littlefield.

Gilbert, M. (2002). Belief and acceptance as features of groups. ProtoSociology, 16, 35-69.

Gilbert, M. (2004). Collective epistemology. Episteme, 1(2), 95-107.

Gilbert, M., \& Pilchman, D. (2014). Belief, acceptance, and what happens in groups. In J. Lackey (Ed.), Essays in collective epistemology. Oxford University Press.

Hakli, R. (2006). Group beliefs and the distinction between belief and acceptance. Cognitive Systems Research, 7, 286-297.

Lackey, J. (2016). What is justified group belief? Philosophical Review, 125(3), 341-396.

Lackey, J. (2020). Group belief: Lessons from lies and bullshit. Aristotelian Society Supplementary, 94(1), 185-208.

Meijers, A (1999). Believing and accepting as a group. In: Belief, cognition, and the will. Tilburg University Press.

Meijers, A. (2002). Collective agents and cognitive attitudes. Protosociology, 16, 70-85.

Quinton, A. (1975). Social objects. Proceedings of the Aristotelian Society, 76, 1-27.

Silva, P. (2019). Justified group belief is evidentially responsible group belief. Episteme, 16(3), 262-281.

Thagard, P. (2010). Explaining economic crises: Are there collective representations? Episteme, 7(3), 266-283.

Tollefsen, D. (2002a). Organizations as true believers. Journal of Social Philosophy, 33(3), 395-410.

Tollefsen, D. (2002b). Challenging epistemic individualism. Protosociology, 16, 86-117.

Tollefsen, D. (2003). Rejecting rejectionism. Protosociology, 18, 389-405. 
Tollefsen, D. (2015). Groups as agents. Polity Press.

Tuomela, R. (1992). Group beliefs. Synthese, 91, 285-318.

Tuomela, R. (2000). Belief versus acceptance. Philosophical Explorations, 3(2), 122-137.

Tuomela, R. (2004). Group knowledge analyzed. Episteme, 1(2), 109-127.

Williams, B. (1970). Deciding to believe. In: Problems of the self. Cambridge University Press, pp. 136-151.

Wray, B. (2001). Collective belief and acceptance. Synthese, 129(3), 319-333.

Wray, B. (2003). What really divides gilbert and the rejectionists? ProtoSociology, 18, 363-376.

Publisher's Note Springer Nature remains neutral with regard to jurisdictional claims in published maps and institutional affiliations. 